\title{
Participación política y candidaturas independientes
}

\section{Miguel Carbonell*}

\section{Sumario:}

I. Introducción

II. Caso Michoacán (2001)

III. Caso del Ayuntamiento de Las Vigas de Ramírez, Veracruz

IV. Avizorando el futuro: a modo de conclusión

* Investigador en el Instituto de Investigaciones Jurídicas de la UNAM. 


\section{Introducción}

Uno de los temas más debatidos dentro del ya extenso ciclo de reformas electorales que ha vivido México en los últimos 30 años tiene que ver con las modalidades de la participación política. ${ }^{1}$ En buena medida, varias de dichas reformas sirvieron para ir dando cauce de expresión política y democrática a fuerzas que antes no tenían manera de integrarse institucionalmente a la vida pública nacional.

Es precisamente en ese contexto en el que se avanza hacia la creación de los diputados plurinominales, se facilita la creación de nuevos partidos, se crean figuras como la de senadores de primera minoría,

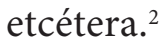

Con todo y eso, es probable que sigan faltando canales que incentiven la participación política en los procesos electorales, sobre todo bajo modalidades que no tengan que pasar por esas fortalezas cerradas en las que actualmente se han convertido los partidos políticos. Mucho se ha discutido sobre la viabilidad, pertinencia, necesidad, riesgos, beneficios, etcétera, de las candidaturas independientes. ${ }^{3}$ No es momento de volver a traer a cuenta ese debate, que sin duda ha servido para que volvamos a pensar cómo deben ser nuestras contiendas electorales y, sobre todo, quiénes deben participar en ellas.

En las páginas que siguen, más que retomar los puntos de vista que se han expresado a favor y en contra de la participación no partidista de ciudadanos en los comicios, lo que haremos será analizar dos sentencias de la Sala Superior del Tribunal Electoral del Poder Judicial de la Federación en las que se analizó el tema. De esa forma, podremos estar en capacidad de apreciar la forma en que la justicia electoral federal ha respondido ante el interés de ciertos ciudadanos por evitar la

1 Un buen panorama comparada sobre las reformas electorales de las últimas décadas se encuentra en Zovatto, Daniel y Orozco Henríquez, José de Jesús (coords.), Reforma política y electoral en América Latina 1978-2007, México, UNAM, Instituto de Investigaciones Jurídicas-IDEA-Internacional, 2008.

2 Para comprender el proceso de cambio político y electoral en México es interesante revisar el libro de Becerra, Ricardo et al., José, La mecánica del cambio político en México. Elecciones, partidos y reformas, 3a. ed., México, Cal y Arena, 2005.

3 Ver, por ejemplo, el ensayo de De la Peza, José Luis, "Candidaturas independientes", en Nohlen, Dieter et al. (comps.), Tratado de derecho electoral comparado de América Latina, 2a. ed., México, FCE, 2007, pp. 613 y ss. 
camisa de fuerza de la postulación a un cargo público exclusivamente a través de un partido.

A fin de cuentas, indagar sobre el contenido de dichas sentencias nos lleva de la mano hacia uno de los temas centrales del debate mexicano de los años recientes: ¿qué arreglos institucionales y bajo qué parámetros de participación, deben regir las elecciones de los cargos públicos?

En el fondo, además, late una cuestión todavía más trascedente, por ser más amplia e incluso previa a la anterior: se trata del importante tema de los sujetos de los derechos fundamentales. ¿Qué sujetos deberían ser los titulares de los derechos fundamentales y, en este caso, de los derechos de participación política? El enfoque general rebasa el ámbito de las elecciones y conecta directamente con asuntos vinculados a los derechos de las personas migrantes, de las personas con discapacidad, del matrimonio homosexual, etcétera. ${ }^{4}$ De ahí, creo, la importancia de saber lo que ha dicho la jurisdicción electoral sobre las vías de participación política no partidista en los procesos electorales.

Las dos sentencias que vamos a comentar son la SUP-JDC-037-2001, resuelta por la Sala Superior el 25 de octubre de 2001 y cuyo encargado del engrose fue el magistrado José de Jesús Orozco Henríquez, y la SUP-JDC-713/2004, resuelta por la propia Sala Superior el 22 de diciembre de 2004, cuyo engrose también estuvo a cargo del mismo magistrado Orozco Henríquez.

\section{Caso Michoacán (2001)}

El primero de los dos casos que vamos a analizar tiene que ver con la solicitud que la parte actora, Guillermo Guillén Monzón, hizo al Consejo General del Instituto Electoral de Michoacán para que se le registrara como candidato sin partido para contender por el cargo de gobernador de ese Estado. Ante la negativa, se plantea el juicio para la protección de los derechos político electorales, dado que el actor estima que los preceptos del Código Electoral local aplicados por el

4 Sobre las cuestiones generales de titularidad de derechos fundamentales, Carbonell, Miguel, Los derechos fundamentales en México, 4a. ed., México, Porrúa, UNAM, CNDH, 2011, capítulo I. 
Instituto violan la fracción II del artículo 35 de la Constitución Política de los Estados Unidos Mexicanos, la cual establece la prerrogativa de todo ciudadano para ser titular del derecho de sufragio pasivo (es decir, el derecho a ser votado).

En ese contexto, lo que la Sala debe determinar es si en la Constitución mexicana o en los tratados internacionales de derechos humanos se encuentra previsto un derecho fundamental a que un ciudadano pueda participar en un proceso electoral bajo la figura de candidato independiente, de tal manera que el legislador no pueda limitar dicho derecho a través de la asignación de una competencia exclusiva a favor de los partidos políticos para efecto de postular a los candidatos a cargos de elección popular.

El razonamiento de la Sala adelanta desde su considerando tercero la conclusión: de lo que dispone el artículo 35 fracción II constitucional no puede desprenderse que el derecho a ser votado tenga un carácter absoluto y que no se pueda establecer límite legal alguno para su ejercicio; de ahí que no resulte inconstitucional ni violatoria del derecho internacional de los derechos humanos la negativa de registro que el Instituto Electoral de Michoacán determinó en contra de lo solicitado por el señor Guillén Monzón.

Los ordenamientos aplicables, dice la Sala en su sentencia, no prohíben las limitaciones o restricciones que pueda determinar la legislación a los derechos político-electorales, ni a los derechos fundamentales o humanos en general; lo que impiden es que tales restricciones sean irracionales, injustificadas, desproporcionadas o que se traduzcan en privar de su esencia a cualquier derecho, fin, principio o valor constitucional o electoral fundamental. ${ }^{5}$

La idea que la Sala repite en distintas partes de su sentencia es que el derecho a ser votado no es absoluto, ya que se le debe considerar como un derecho de base constitucional, pero de configuración legal.

No se trata, en esa virtud, de emitir un juicio de todo o nada, de blanco o negro, sobre la constitucionalidad de una ley que señale que solamente podrán ser registrados los candidatos a cargos de elección popular que sean postulados por los partidos. Se trata más bien, de acuerdo a los argumentos esgrimidos por la Sala, de analizar si los requisitos previstos por el legislador se ajustan o no al mandato de

Sobre el tema de los límites de los derechos, Brage Camazano, Joaquín, Los límites a los derechos fundamentales, Madrid, Dykinson, 2004. 
racionalidad, proporcionalidad y respeto al contenido esencial del derecho de sufragio pasivo.

Para desarrollar su argumento, la Sala llama la atención sobre la manera en que está redactada la fracción II del artículo 35 constitucional, en cuya última parte se señala que el derecho a ser votado puede estar condicionado al cumplimiento de "las calidades que establezca la ley". De ese modo, la Constitución le abre una puerta interesante al legislador para incidir en la regulación del derecho en cuestión.

¿Qué debe entender por "calidades", a efecto de poder determinar el alcance de la remisión que hace el artículo 35 fracción II a la ley? La Sala considera que por calidad, en el contexto de la citada fracción, debe entenderse un requisito, circunstancia o condición necesaria establecida por el legislador ordinario, la cual debe satisfacerse para ejercer el derecho de ser votado.

Tales requisitos o circunstancias, señala más adelante la Sala, no deben ser absurdos, inútiles o de imposible realización, dado que si tuvieran esas características terminarían por hacer nugatorio el ejercicio del derecho, incidiendo de esa manera en su contenido esencial. ${ }^{6}$

En una parte muy relevante de la sentencia, la Sala señala que no existe ninguna disposición constitucional que otorgue el monopolio de la postulación de candidatos a los partidos políticos, excepción hecha de los diputados y senadores por vía plurinominal, ya que ellos sí deben estar en una lista que presentan solamente los partidos políticos.

A partir de esta consideración de la Sala, podemos concluir que el legislador tiene la facultad de crear la figura de las candidaturas independientes si así lo considera pertinente. Si lo hace, no estaría violando la Constitución.

De hecho, en su momento el legislador podría incluso permitir que entren en la competencia electoral personas morales distintas a los partidos pero que persigan fines políticos, así como personas físicas no organizadas o no afiliadas en torno a una persona moral. La Sala señala que el hecho de que los partidos políticos tengan entre sus objetivos, por mandato constitucional, la postulación de candidatos, no excluye que lo puedan tener otras entidades o que pueda haber candidatos sin afiliación.

6 Sobre el concepto de "contenido esencial" de los derechos puede verse la voz "Contenido esencial de los derechos fundamentales" escrita por Prieto Sanchís, Luis, en Carbonell, Miguel (coord.), Diccionario de derecho constitucional, 3a. ed., México, Porrúa, UNAM, 2009, t. I, pp. 235 y ss. 
Ahora bien, la existencia de las candidaturas independientes debe considerarse como una posibilidad, pero no como una obligación constitucional dirigida al legislador. No existe un mandato que obligue a prever las candidaturas independientes, dice la Sala.

En la sentencia hay también algunas consideraciones interesantes e importantes sobre el derecho de asociación. ${ }^{7}$ En particular, la Sala le responde a la parte actora que la legislación electoral de Michoacán no viola su libertad de asociación al prever que solamente los partidos políticos puedan postular candidatos, ya que para ser candidato no se requiere ser miembro o afiliado a un partido. De esa forma, su libertad negativa de no asociarse (que forma parte del derecho de asociación entendido en sentido amplio), estaría salvaguardada, ya que el legislador no obliga a la afiliación partidista, sino que limita la participación de candidatos no postulados por un partido, lo cual es una cuestión distinta.

De hecho, la sentencia señala que ninguna de las normas constitucionales o legales aplicables exige, en forma alguna, la afiliación obligatoria a un determinado partido para poder ser postulado como candidato. Cada ciudadano cuenta con la libertad para elegir el partido político por el que quiere participar; incluso puede elegir no afiliarse a ningún partido y de todas formas ser postulado por alguno de ellos. Pero además tiene la opción de que, si no le agrada ninguna de las opciones partidistas existentes, trabaje para formar un nuevo partido político. De esa manera se resguarda y garantiza el derecho de asociación.

La Sala se ocupa también de señalar las disfuncionalidades que acontecerían en el curso del proceso electoral en el caso de que se ordenara el registro de candidatos independientes sin contar con la debida regulación por parte del legislador. Se trata de un razonamiento orientado a la práctica, que sin duda resulta valioso para darnos cuenta de la absoluta relevancia que cobra el desarrollo legislativo para que - en su momento- las candidaturas independientes puedan en el futuro del derecho electoral mexicano venir a enriquecer una competencia electoral y no a demeritar las condiciones bajo las cuales se lleva a cabo.

Así por ejemplo, la Sala señala que las candidaturas independientes sin regulación alguna podrían atraer a un número excesivo de partici-

Carbonell, Miguel, "La libertad de asociación en el constitucionalismo de América Latina”, Direitos fundamentais \& Justica, Porto Alegre, año 4, núm. 12, julio-septiembre de 2010, pp. 13-24. 
pantes, lo que terminaría por producir una "total confusión por saturación". Además, la preparación del material electoral se complicaría; no sería extraño tener que imprimir boletas electorales con cientos o quizá miles de nombres, con las consiguientes dificultades que eso supone. Por otro lado, en caso de que fueran muchos los candidatos, la votación se podría llegar a fragmentar de un modo tal que el número de votos obtenido por el ganador podría ser casi irrelevante, lo que iría en demérito de la legitimidad con que deben estar revestidos los órganos representativos.

A la sentencia que comentamos la acompaña un "voto aclaratorio" formulado por la magistrada Alfonsina Berta Navarro y por el magistrado Eloy Fuentes Cerda en el que se señala que, según el entender de ambos magistrados, la Constitución mexicana no permite las candidaturas independientes, ya que el sistema electoral se basa precisamente en los partidos políticos. Según los magistrados mencionados, "si no es a través de los partidos políticos, no es posible el acceso de los ciudadanos al poder público, es decir, a los cargos de elección popular", de modo que "no existe la posibilidad de que candidatos independientes pudieran participar en las elecciones populares".

En un voto concurrente los magistrados Mauro Miguel Reyes Zapata y Leonel Castillo González consideran que la Constitución sí obliga al legislador a prever la figura de las candidaturas independientes, si bien no pueden reconocerse en ausencia de dicha regulación. Lo que sucede en el caso de Michoacán, señalan, es que estamos frente a una laguna, la cual no puede ser colmada convenientemente (en el caso concreto) por los instrumentos que tiene a su alcance la función jurisdiccional. ${ }^{8}$

\section{Caso del Ayuntamiento de Las Vigas de Ramírez, Veracruz}

Este caso también trata del alcance del derecho de sufragio pasivo, previsto por la fracción II del artículo 35 constitucional y de los re-

8 Sobre el tema de las omisiones legislativas y su control constitucional puede verse Carbonell, Miguel (coord.), En busca de las normas ausentes. Ensayos sobre la inconstitucionalidad por omisión, 2a. ed., México, UNAM, Instituto de Investigaciones Jurídicas, 2007. 
quisitos para poder competir en una elección sin ser postulado por un partido político. Pero presenta algunas diferencias interesantes respecto del caso de Michoacán, sobre todo por lo que respecta a los hechos que suscitan el juicio, dado que los razonamientos de la Sala Superior son muy semejantes en ambos casos.

En el caso de Veracruz se les niega el registro a unos aspirantes ciudadanos, en la elección municipal, aunque se les deja libre la posibilidad de que participen como candidatos no registrados, que es una figura prevista por la legislación local.

Sucede que los ciudadanos en cuestión obtuvieron el mayor número de votos, gracias sobre todo a que repartieron entre sus simpatizantes una especie de calcomanía que debía ser adherida a la boleta electoral al momento de emitir el sufragio, en la parte de la misma que estaba destinada precisamente a los candidatos no registrados. En esa virtud, la parte actora en el juicio resuelto por la Sala Superior reclama su triunfo y pide que se le entregue la respectiva constancia.

La Sala estima que los votos no pueden ser considerados como válidos ni eficaces a efecto de determinar el resultado electoral, ya que los interesados no cumplieron con el requisito que señala la legislación electoral de Veracruz, en el sentido de que debían ser postulados por un partido político y haber obtenido el registro por parte de la autoridad administrativa electoral.

La Sala admite que los votos que son emitidos a favor de candidatos no registrados no pueden considerarse como nulos, pero tampoco son válidos dado que les falta el requisito legal de que los candidatos en cuestión hayan sido registrados por la autoridad administrativa electoral competente, en la etapa de preparación del proceso electoral y siempre a propuesta de un partido político.

El procedimiento de registro de candidatos, señala la Sala, es una fase fundamental del proceso electoral, puesto que tiene como finalidad que las autoridades electorales conozcan a quienes serán los contendientes a fin de vigilar adecuadamente que acaten las disposiciones que les son aplicables; principalmente aquellas que regulan el desarrollo del proceso electoral, las campañas y el origen, monto y aplicación de los recursos económicos empleados.

La Sala, en este contexto, vuelve a retomar los argumentos ya expresados en el caso de la legislación electoral de Michoacán, en el sentido de que el ejercicio del derecho de sufragio pasivo debe ser regulado a través de una ley, la cual debe respetar el contenido esencial del dere- 
cho y ser armónica con otros derechos fundamentales previstos en el orden jurídico nacional (como por ejemplo el derecho de igualdad). Se repite también el argumento de las "calidades" a las que alude la fracción II del artículo 35 constitucional, como una forma de comprensión del derecho de sufragio pasivo que lo aleja de un posible contenido absoluto.

También en este caso la Sala se hace cargo de las cuestiones prácticas que están presentes en la concurrencia a un proceso electoral de candidatos no registrados. Señala que respecto de ellos se hace imposible la vigilancia que tiene el deber de desarrollar la autoridad electoral, no hay forma de saber si se ajustaron o no a los topes de campaña y tampoco se les puede hacer rendir los informes correspondientes. Por todo ello se estima que su participación en el proceso electoral es disfuncional y les otorga una ventaja indebida respecto a los demás contendientes, ya que no están sujetos a las obligaciones previstas por la legislación electoral.

Los votos emitidos a favor de candidatos no registrados no pueden ser considerados como válidos, pues únicamente tienen por efecto servir a las tareas de la autoridad electoral relativas a la estadística electoral, así como respetar la libre manifestación de las ideas de los votantes.

La Sala estima que el requisito de que se cuente con el registro como candidato otorgado por la autoridad electoral, no solamente no viola ningún derecho fundamental, sino que hace posible salvaguardar el derecho de acceder, en condiciones de igualdad, a los cargos públicos.

En este caso los magistrados Leonel Castillo González y Mauro Miguel Reyes Zapata emiten nuevamente un voto particular, en el que consideran que los votos emitidos a favor de candidatos no registrados deben surtir plenamente todos los efectos legales, ya que recogen la voluntad popular expresada en las urnas. Ambos magistrados consideran que si un candidato no registrado obtiene la mayoría de votos, debe tener la posibilidad jurídica de acceder al cargo en cuestión, ya que "las consecuencias otorgadas al voto por disposición legal deben ser totales". De otro modo se violentaría el principio de mayoría que rige a las elecciones.

Respecto del uso de las estampas que fueron colocadas en las boletas, para identificar el voto a favor de candidatos no registrados, los magistrados autores del voto particular estiman que es correcto $\mathrm{y}$ funcional, ya que de esa manera reducen las desventajas que tienen 
los candidatos no registrados respecto de los registrados, los cuales cuentan con financiamiento público, acceso a medios y demás prerrogativas de las que carecen los primeros.

También emitió un voto particular el magistrado José Luis de la Peza, según el cual los votos emitidos a favor de candidatos no registrados debían considerarse como válidos, para evitar que se estuviera ante una privación de derechos político-electorales. En todo caso, señaló De la Peza, los tribunales podrían revisar que los candidatos no registrados no hubieran incurrido en irregularidades que pusieran en cuestión su victoria electoral, ya que están igualmente sujetos a lo que disponga la legislación correspondiente.

\section{Avizorando el futuro: a modo de conclusión}

El tema de las candidaturas independientes no solamente ha sido analizado por la jurisdicción interna, sino también por la Corte Interamericana de Derechos Humanos en el caso de Jorge Castañeda Gutman contra México (aunque respecto de los requisitos para ejercer los derechos de participación política ya existía un antecedente importante en la sentencia del caso Yatama contra Nicaragua). ${ }^{9}$

El razonamiento de la Corte Interamericana es parecido al de la Sala Superior, en la medida en que no admite que los Estados parte de la Convención Americana de Derechos Humanos estén obligados a prever la figura de las candidaturas independientes, dado que el derecho de sufragio pasivo es un derecho de configuración legal.

Ahora bien, lo importante es que el tema sigue abierto y que probablemente debería ser atendido por el legislador ordinario, como una medida que (si está bien regulada), podría servir como una fuente de oxigenación de un panorama político que por momentos parece sofocante. Hay que considerar que cada vez se ha vuelto más complicada la creación de nuevos partidos, por los elevados requisitos que exige la legislación correspondiente. Pero además, hay que tener en cuenta que un porcentaje de ciudadanos no se siente representado por ninguna de las opciones partidistas que existen.

9 Ferrer Mac-Gregor, Eduardo y Silva García, Fernando, El caso Castañeda ante la Corte Interamericana de Derechos Humanos, México, Porrúa, 2009. 
Lo ideal sería que, si el legislador mexicano decide un día regular la figura de las candidaturas independientes, repare en las experiencias que ya se tienen al respecto en América Latina. Recordemos que, de los 18 países democráticos de la región, solamente siete mantienen un monopolio absoluto de los partidos políticos para la postulación de candidatos: Argentina, Brasil, Costa Rica, El Salvador, México, Nicaragua y Uruguay. Por su parte, países como Bolivia, Chile, Colombia, Ecuador, Honduras, Paraguay, República Dominicana, Venezuela, Panamá, Perú y Guatemala prevén en algún grado y medida la figura de las candidaturas independientes. ${ }^{10}$

Considerando la experiencia latinoamericana, Zovatto y Orozco señalan que

estas nuevas formas de representación política en ciertos países cuentan con la aceptación de grandes sectores de la ciudadanía... (aunque) su reciente introducción en la vida política de la región no nos permite determinar con certeza elementos definitivos de juicio para determinar su impacto y afirmar si estos mecanismos han contribuido o no a mejorar la representatividad y la canalización de los intereses de la ciudadanía. ${ }^{11}$

Finalmente, lo que hay que considerar es que, como bien lo ha señalado la Sala Superior en las dos sentencias que hemos comentado, las candidaturas independientes no están en modo alguno prohibidas en el sistema jurídico mexicano, por lo que debe ser el legislador el que valore los términos, condiciones y requisitos para que puedan existir y sean funcionales para fortalecer el régimen constitucional y democrático de México. Ojalá que así sea.

10 Véanse los datos que figuran en Zovatto, Daniel y Orozco Henríquez, José de Jesús, "Reforma política y electoral en América Latina 1978-2007: lectura regional comparada", en id. (coords.), Reforma política y electoral en América Latina 1978-2007, cit., pp. 184 y 185 (cuadro 26).

11 Ibidem, p. 187. 